\title{
Bandwidth Enhancement of a Bell-shaped UWB Antenna for Indoor Localization Systems
}

\author{
Mohamed Salah Karoui \\ National Engineering School of Sfax \\ University of Sfax \\ ENIS, LETI Laboratory \\ Sfax, Tunisia \\ mohamedsalah.karoui@issatm.rnu.tn \\ Mongi Lahiani \\ National Engineering School of S fax \\ University of Sfax \\ ENIS, LETI Laboratory \\ Sfax, Tunisia \\ mongi.lahiani@enis.rnu.tn
}

\author{
Nadia Ghariani \\ National Engineering School of S fax \\ University of S fax \\ ENIS, LETI Laboratory \\ Sfax, Tunisia \\ ghariani.nadia@gmail.com \\ Hamadi Ghariani \\ National Engineering School of S fax \\ University of S fax \\ ENIS, LETI Laboratory \\ Sfax, Tunisia \\ hamadi.ghariani@enis.rnu.tn
}

\begin{abstract}
In this paper, a simple method of enhancing the bandwidth of the Bell-shaped UWB Antenna for indoor localization systems is proposed. Therefore, a modified version of the bell-shaped Ultra-Wide Band (UWB) antenna for indoor localization systems is presented. The proposed antenna is printed on a low-cost FR-4 substrate of $21 \times 27 \times 1.6 \mathrm{~mm}^{3}$ size. It is composed of a bell-shaped radiating patch and a multi-slotted ground plane. The measured results show that the proposed antenna has an impedance bandwidth of about $11.2 \mathrm{GHz}$ ranging from $3.16 \mathrm{GHz}$ to $14.36 \mathrm{GHz}$ at $\mathrm{S} 11<-10 \mathrm{~dB}$. Compared to the original version, an enhancement of about $5.56 \mathrm{GHz}$ in the measured impedance bandwidth was observed.
\end{abstract}

Keywords-localization systems; printed monopole antennas; slotted ground plane; ultra wideband systems.

\section{INTRODUCTION}

During the last years, a large variety of antennas have been implemented for indoor localization systems. The selection of the appropriate antenna depends on many parameters and has considerable effects on the performance of the system. The study presented in [1] sums up the antenna requirements for indoor localization systems and more particularly for reference nodes. These requirements are more or less stringent, depending on the localization technique, the localization model, the metric being used during localization process and the nature of the signal being processed. As Impulse Radio Ultra Wide Band (IR-UWB) -based localization systems are commonly characterized by the transmission of ultra-short pulses over a large bandwidth, the smallest distortions introduced by the antennas lead to large localization errors. To reduce the effect of the antenna on localization accuracy, the designed antenna should respect these characteristics $[1,2]$ :

- Large bandwidth; ideally from $3.1 \mathrm{GHz}$ to $10.6 \mathrm{GHz}$
- Linear phase and constant group delay over the entire bandwidth

- High radiation efficiency, typically $>70 \%$

- Omni-directional and stable radiation pattern

- Flat gain over the entire bandwidth

- Small size and low cost

The implementation of antennas with circular polarization over the entire bandwidth is another important characteristic for UWB antennas used for reference unit. This parameter enables the detection of targets with unknown polarization [3]. To achieve all these requirements, several antenna structures have been proposed, including 3D and planar forms. The microstrip patch antennas have gained more attention, due to their low profile, low cost, ease of fabrication, and good radiation properties. Unfortunately, they suffer from limited bandwidth. To improve their bandwidth, antenna designers have used several techniques including [2, 4-7]:

- Various feeding techniques

- Slot antenna geometry

- Addition of a slot on the radiating patch

- Insertion of an additional stub on the patch

- Addition of steps to the lower edge of the patch

- Insertion of multiple slots in the ground plane

In this study, a compact microstrip line-fed UWB antenna with partial ground plane is presented. Three slots with the same dimensions were inserted in the top edge of the ground 
plane. With this technique, an enhancement of $5.56 \mathrm{GHz}$ in the measured impedance bandwidth of the antenna was achieved.

\section{ANTENNA CONFIGURATION}

The proposed antenna is realized on an FR-4 substrate of size $\left(\mathrm{W}_{\text {sub }}=21 \mathrm{~mm} \times \mathrm{L}_{\text {sub }}=27 \mathrm{~mm}\right)$ with height $\mathrm{h}=1.6 \mathrm{~mm}$, relative permittivity $\varepsilon_{\mathrm{r}}=4.4$, and loss tangent $\tan \delta=0.02$.

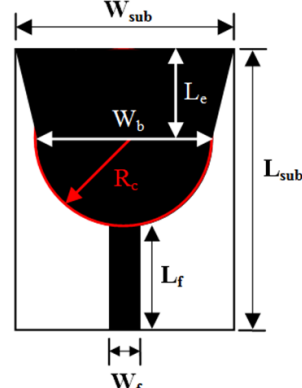

(a)

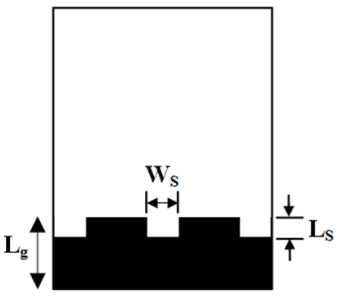

(b)
Fig. 1. Geometry of the proposed antenna: (a) front view, (b) back view.

As shown in Figure 1, the front view is composed of a bellshaped radiating patch fed by a $50 \Omega$ microstrip feed line with width $\mathrm{W}_{\mathrm{f}}=3 \mathrm{~mm}$ and length $\mathrm{L}_{\mathrm{f}}=10 \mathrm{~mm}$. The radiating patch has the same shape and dimensions as the antenna presented in [8]. It is formed by the association of a trapezoid with dimensions $\mathrm{W}_{\mathrm{b}}=17 \mathrm{~mm}, \mathrm{~W}_{\text {sub }}=21 \mathrm{~mm}, \mathrm{~L}_{\mathrm{e}}=8.5 \mathrm{~mm}$ and $\mathrm{a}$ semicircle of radius $\mathrm{R}_{\mathrm{C}}=8.5 \mathrm{~mm}$. The back view of the structure consists of a partial ground plane with length $\mathrm{L}_{\mathrm{g}}=7 \mathrm{~mm}$. Three rectangular slots with size of $\mathrm{W}_{\mathrm{s}}=3 \mathrm{~mm} \times$ $\mathrm{L}_{\mathrm{s}}=2 \mathrm{~mm}$ are added in the upper edge of the ground plane to enhance the impedance bandwidth of the antenna.

\section{PARAMETRIC STUDY}

To meet the UWB antenna requirements, a parametric study was carried out using the High Frequency Simulation Software (HFSS) v.13. To achieve the largest impedance bandwidth and to find the optimal antenna parameters, the effects of varying slot number, slot dimension, and slot positions were analyzed. During the simulations, an SMA coaxial connector was connected to the feed line to obtain more realistic results. The ground plane shape and dimensions are sensitive parameters in UWB antenna design [9-12]. Actually, the distance between the ground plane and the feed line changes the input impedance and hence the operating bandwidth of the antenna giving a better or a worst return loss. By inserting first a slot in the upper edge of the ground plane, the gap between the feed line and the ground plane is enlarged resulting in a change on the impedance bandwidth. The tuning results of slot size and position are presented in Figures 2 and 3 respectively. It can be seen from the figures, that a slot of dimensions $\mathrm{W}_{\mathrm{S}}=3 \mathrm{~mm} \times \mathrm{L}_{\mathrm{S}}$ $=2 \mathrm{~mm}$ placed in the middle of the ground plane gives the largest impedance bandwidth. According to the simulated results, the $-10 \mathrm{~dB}$ return loss bandwidth of the antenna is about $7.89 \mathrm{GHz}$ ranging from $3.16 \mathrm{GHz}$ to $11.05 \mathrm{GHz}$. To further enhance the impedance bandwidth of the antenna and to cover the entire UWB frequency band, more slots were inserted in the upper edge of the ground plane. The simulation results of S11 as a function of the number of slots are shown in Figure 4.

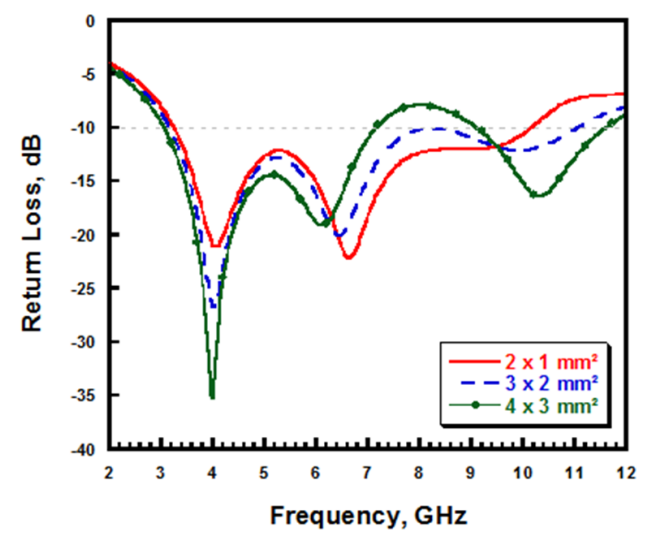

Fig. 2. Variation of the S11 for different slot dimensions.

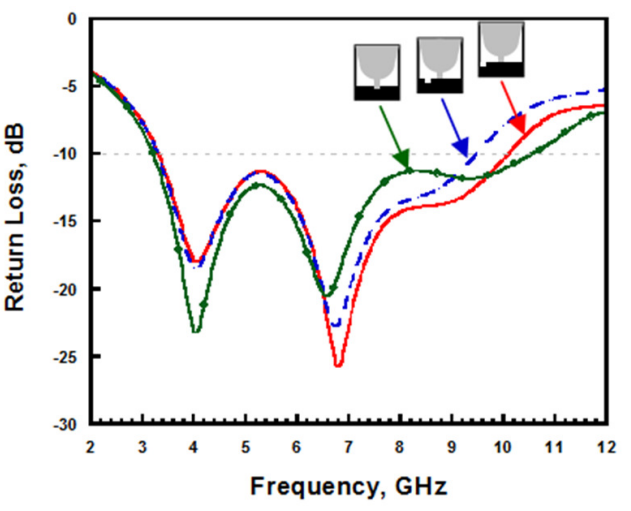

Fig. 3. Variation of the S11 for different slot positions.

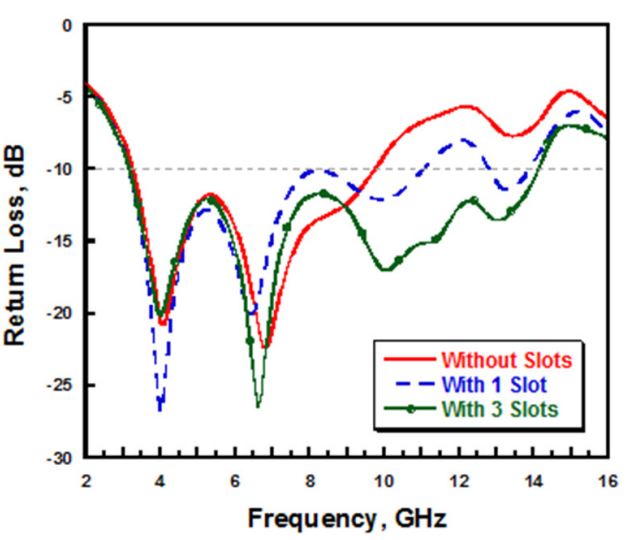

Fig. 4. Variation of the $\mathrm{S} 11$ as a function of the number of slots.

It can be observed from Figure 4 that the impedance bandwidth of the proposed antenna is getting larger as the number of slots increases. Actually, with the insertion of three slots in the ground plane, an enhancement of $4.47 \mathrm{GHz}$ in the simulated impedance bandwidth is noticed. The proposed antenna covers the frequency band from $3.16 \mathrm{GHz}$ to $14.11 \mathrm{GHz}$, thus ensuring the coverage of almost the entire UWB frequency band. These results confirm the effect of ground plane on impedance bandwidth and prove the effectiveness of slot insertion on impedance bandwidth enhancement. 


\section{RESULTS AND DISCUSSION}

The prototype of the proposed antenna was fabricated on a low cost FR-4 substrate of compact size (Figure 5). All the antenna parameters were measured in the IMEP-LAHC research laboratory (Grenoble, France). The impedance characteristics were measured using The ANRITSU 37369A $(40 \mathrm{MHz}-40 \mathrm{GHz})$ vector network analyzer while the gain and the radiation pattern were measured using an SATIMO anechoic chamber.

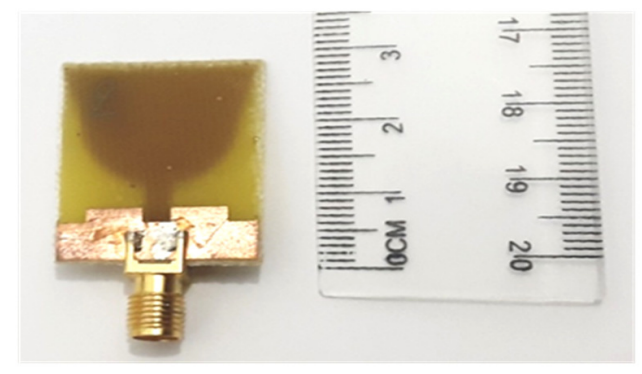

Fig. 5. Picture of the realized antenna.

\section{A. Impedance Bandwidth}

The simulated and measured return losses of the proposed antenna are presented in Figure 6. As shown in the Figure, the measured impedance bandwidth of the proposed antenna is about $11.2 \mathrm{GHz}$ ranging from $3.16 \mathrm{GHz}$ to $14.36 \mathrm{GHz}$ while the simulated impedance bandwidth is about $10.95 \mathrm{GHz}$ ranging from $3.16 \mathrm{GHz}$ to $14.11 \mathrm{GHz}$. There is a good agreement between the simulation and the measurement results with a slight offset at the resonant frequencies and the high frequency. These discrepancies are mainly caused by the connector soldering, the fabrication process, and the nature of the substrate.

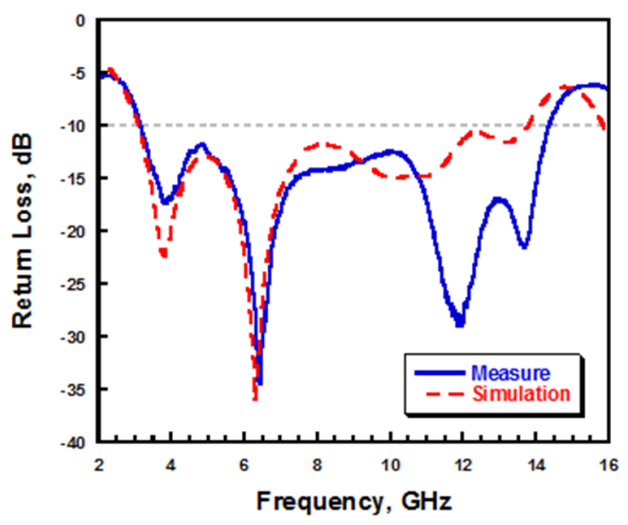

Fig. 6. Simulated and measured return loss.

\section{B. Group Delay}

The simulated group delay of the proposed antenna over the frequency band from $2 \mathrm{GHz}$ to $16 \mathrm{GHz}$ is presented in Figure 7. The simulation results show that the antenna has a group delay less than 0.5 ns over the UWB frequency band and greater than 1ns outside this band. These results prove that the antenna introduces a low distortion on the transmitted UWB signal.

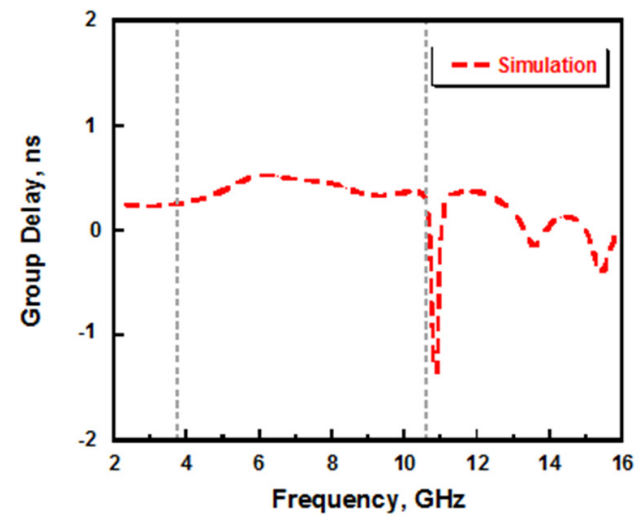

Fig. 7. Simulated group delay.

\section{Peak Gain}

The simulated and measured peak gains of the proposed antenna in the frequency band from $2 \mathrm{GHz}$ to $16 \mathrm{GHz}$ are presented in Figure 8. We see that the gains are larger than $1.8 \mathrm{dBi}$ for frequencies above $3 \mathrm{GHz}$. The measured gain varies from $1.82 \mathrm{dBi}$ to $4 \mathrm{dBi}$ in the UWB band with a peak of $4.1 \mathrm{dBi}$ at $6.9 \mathrm{GHz}$ while the simulated gain varies from $0 \mathrm{dBi}$ to $4.38 \mathrm{dBi}$ with a peak of $4.38 \mathrm{dBi}$ at $10.3 \mathrm{GHz}$. Actually, there is a slight difference between simulation and measurement results. This offset is due to the difference in the number of frequency points and the number of cuts taken during measurements.

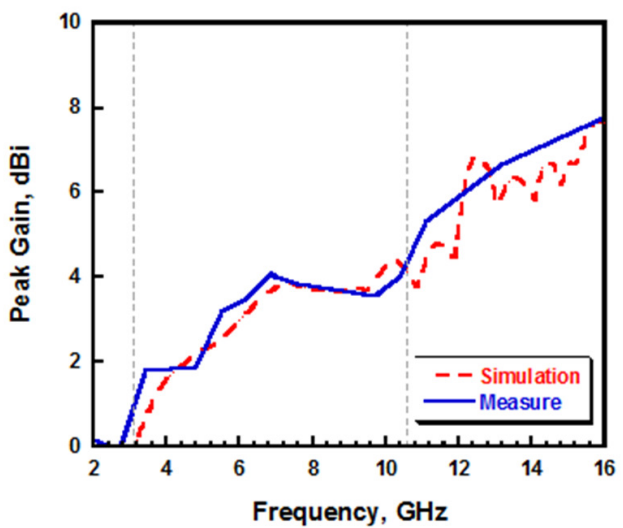

Fig. 8. Simulated and measured peak gain.

\section{Radiation Pattern}

Figure 9 illustrates the simulated and measured radiation patterns of the antenna in the E-plane and the H-plane at different frequencies $(4.1 \mathrm{GHz}, 7 \mathrm{GHz}, 10 \mathrm{GHz}$ and $13 \mathrm{GHz})$. The radiation pattern results show a good match between simulation and measurements with a visible offset especially at $4.1 \mathrm{GHz}$ and $10 \mathrm{GHz}$ frequencies. As shown in Figure 9, the radiation patterns of the proposed antenna are nearly omnidirectional and stable in both planes.

\section{E. Radiation Efficiency}

The simulated radiation efficiency of the proposed antenna is depicted in Figure 10. It can be seen that the proposed antenna has a maximum radiation efficiency of $98.44 \%$ at $8.6 \mathrm{GHz}$ with an average of $95.78 \%$. 
(a)
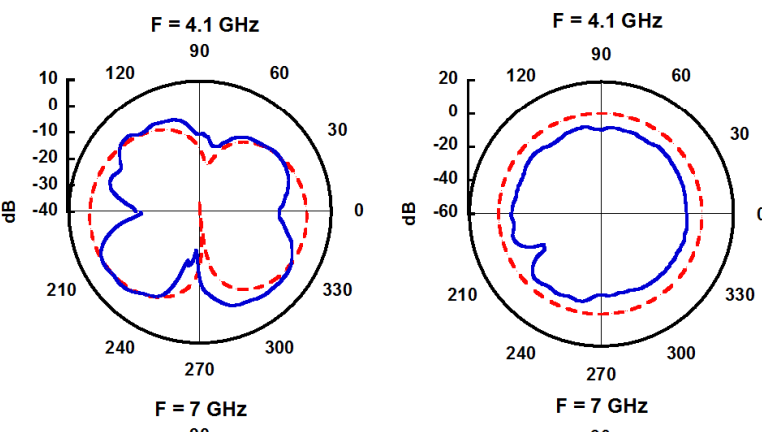

(b)

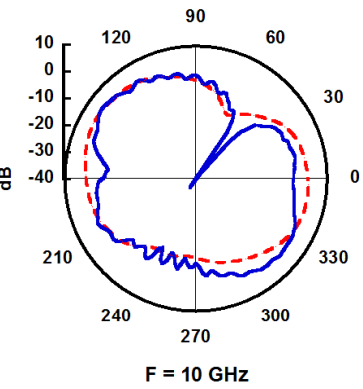

(c)
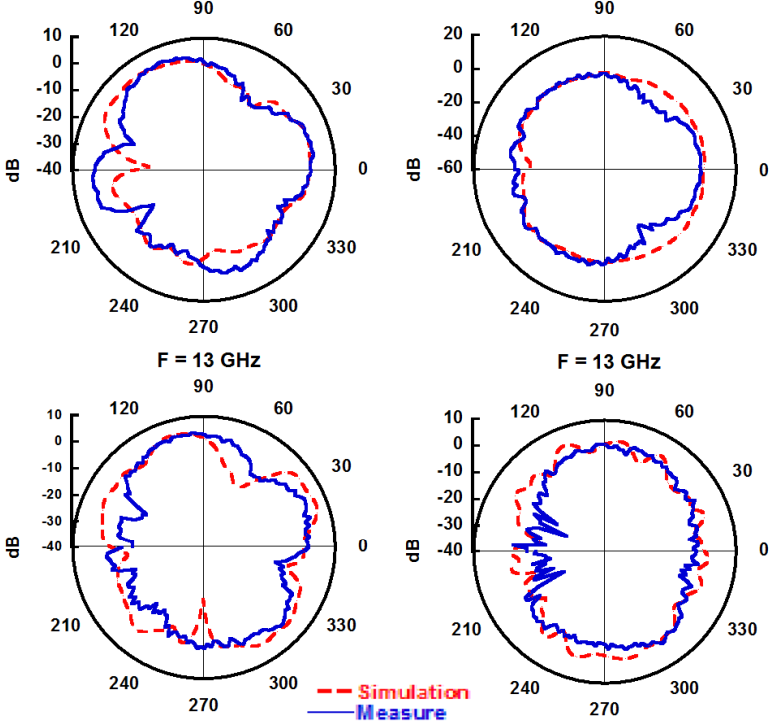

Fig. 9. Simulated and measured radiation patterns (left: E-plane, right: Hplane) at: (a) $4.1 \mathrm{GHz}$, (b) $7 \mathrm{GHz}$, (c) $10 \mathrm{GHz}$, and (d) $13 \mathrm{GHz}$.

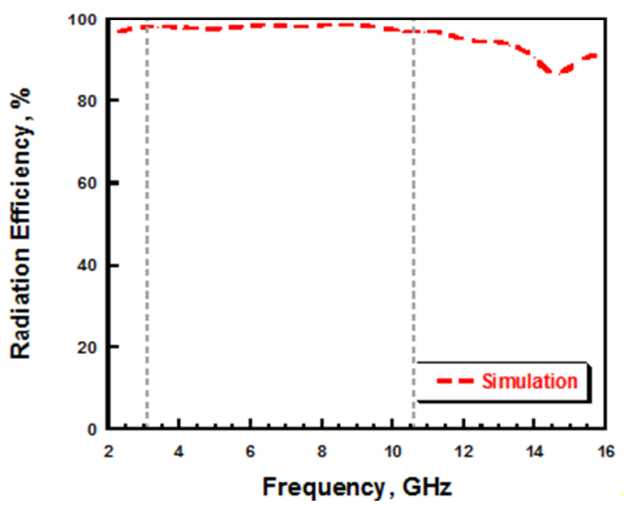

Fig. 10. Simulated radiation efficiency.

\section{COMPARATIVE STUDY}

A comparative study between antennas with slotted ground plane referenced in the literature and the proposed antenna is shown in Table I. The comparative parameters are impedance bandwidth, antenna dimensions, fractional bandwidth and maximum gain. The proposed antenna has the most compact size, a large impedance bandwidth, a high fractional bandwidth but a low gain. It is a good compromise between bandwidth and size. Fortunately, it covers the entire UWB frequency band, but in comparison with other structures, the antenna presented in [2] has larger bandwidth and gain.

TABLE I. BANDWIDTH, DIMENSIONS, FRACTIONAL BANDWIDTH AND GAIN COMPARISON

\begin{tabular}{|c|c|c|c|c|}
\hline Antenna & $\begin{array}{c}-\mathbf{1 0 d B} \text { Bandwidth } \\
(\mathbf{G H z})\end{array}$ & $\begin{array}{c}\text { Dimensions } \\
\left(\mathbf{m m}^{\mathbf{2}}\right)\end{array}$ & $\begin{array}{c}\text { FBW } \\
\mathbf{( \% )}\end{array}$ & $\begin{array}{c}\text { Max gain } \\
(\mathbf{d B i})\end{array}$ \\
\hline$[2]$ & $2.57-16.72$ & $30 \times 22$ & 146.7 & 6.27 \\
\hline$[4]$ & $2.6-12.3$ & $39 \times 40$ & 130.2 & 5.52 \\
\hline$[13]$ & $3.66-14$ & $24 \times 36$ & 117.1 & - \\
\hline$[14]$ & $3.8-12$ & $28 \times 29$ & 103.79 & 4.5 \\
\hline$[15]$ & $3.09-10.85$ & $30 \times 30$ & 111.33 & - \\
\hline$[16]$ & $3.1-10.6$ & $32 \times 40.57$ & 109.49 & - \\
\hline Proposed & $3.16-14.36$ & $27 \times 21$ & 127.85 & 4.1 \\
\hline
\end{tabular}

\section{CONCLUSION}

In this study, a compact and low cost microstrip bell-shaped patch antenna with three slots in the ground plane has been designed and fabricated. The return loss results prove that the insertion of rectangular slots on the upper edge of the ground plane improves the impedance bandwidth of the antenna. Indeed, compared to the original version, the measurement results show a bandwidth enhancement of about $5.56 \mathrm{GHz}$, thus reaching $11.2 \mathrm{GHz}$. The proposed antenna has a large impedance bandwidth ranging from $3.16 \mathrm{GHz}$ to $14.36 \mathrm{GHz}$, which covers the entire UWB frequency band. Consequently, it remains suitable for being used in UWB localization systems with its stable gain, its low group delay and its nearly omnidirectional radiation patterns in both planes.

\section{ACKNOWLEDGMENT}

The authors would like to thank Dr. Than Phu Vuong, head of the IMEP-LAHC laboratory in Grenoble, France.

\section{REFERENCES}

[1] L. Brás, N. B. Carvalho, P. Pinho, L. Kulas, and K. Nyka, "A Review of Antennas for Indoor Positioning Systems," International Journal of Antennas and Propagation, vol. 2012, Dec. 2012, Art. no. e953269, https://doi.org/10.1155/2012/953269.

[2] R. Azim, M. T. Islam, N. Misran, S. W. Cheung, and Y. Yamada, "Planar UWB antenna with multi-slotted ground plane," Microwave and Optical Technology Letters, vol. 53, no. 5, pp. 966-968, 2011, https://doi.org/10.1002/mop.25950.

[3] S. Mao, J. Yeh, and S. Chen, "Ultrawideband Circularly Polarized Spiral Antenna Using Integrated Balun With Application to Time-Domain Target Detection," IEEE Transactions on Antennas and Propagation, vol. 57, no. 7, pp. 1914-1920, Jul. 2009, https://doi.org/10.1109/ TAP.2009.2021883

[4] R. Azim, M. T. Islam, and N. Misran, "Microstrip Line-fed Printed Planar Monopole Antenna for UWB Applications," Arabian Journal for Science and Engineering, vol. 38, no. 9, pp. 2415-2422, Sep. 2013, https://doi.org/10.1007/s13369-013-0553-x. 
[5] D. Tran, A. Szilagyi, I. E. Lager, P. Aubry, L. P. Ligthart, and A. Yarovoy, "A super wideband antenna," in Proceedings of the 5th European Conference on Antennas and Propagation (EUCAP), Rome, Italy, Apr. 2011, pp. 2656-2660.

[6] C. P. Lee and C. K. Chakrabarty, "Ultra Wideband Microstrip Diamond Slotted Patch Antenna with Enhanced Bandwidth," International Journal of Communications, Network and System Sciences, vol. 4, no. 7, pp. 468-474, Jul. 2011, https://doi.org/10.4236/ijcns.2011.47057.

[7] H. Alsaif, "Highly Compact Design of Trimmed Patch with Modified Partial Ground Structure for Extreme-Wideband Systems," Engineering, Technology \& Applied Science Research, vol. 7, no. 5, pp. 1918-1921, Oct. 2017, https://doi.org/10.48084/etasr.1416.

[8] N. Ghariani, M. S. Karoui, M. Chaoui, M. Lahiani, and H. Ghariani, "Design of a Bell-Shaped Ultra Wideband Antenna for Indoor Localization System," International Journal on Communications Antenna and Propagation, vol. 5, no. 6, pp. 323-327-327, Dec. 2015, https://doi.org/10.15866/irecap.v5i6.7666.

[9] X. L. Bao and M. J. Ammann, "Investigation on UWB printed monopole antenna with rectangular slitted groundplane," Microwave and Optical Technology Letters, vol. 49, no. 7, pp. 1585-1587, 2007, https://doi.org/ 10.1002/mop. 22524

[10] M. T. Islam and R. Azim, "Recent Trends in Printed Ultra-Wideband (UWB) Antennas," Advancement in Microstrip Antennas with Recent Applications, Mar. 2013, https://doi.org/10.5772/52056.

[11] Y. Lu, Y. Huang, H. T. Chattha, and P. Cao, "Reducing Ground-Plane Effects on UWB Monopole Antennas," IEEE Antennas and Wireless Propagation Letters, vol. 10, pp. 147-150, 2011, https://doi.org/ 10.1109/LAWP.2011.2119459.

[12] P. C. Ooi and K. T. Selvan, "The Effect of Ground Plane on the Performance of a Square Loop CPW-Fed Printed Antenna," Progress In Electromagnetics Research, vol. 19, pp. 103-111, 2010, https://doi.org/ 10.2528/PIERL10102907.

[13] Q. Ain and N. Chattoraj, "A Compact Novel Tapered U Slot Ultra Wideband Antenna," International Journal of Applied Science and Engineering, vol. 11, no. 3, pp. 301-315, 2013, https://doi.org/10.6703/ IJASE.2013.11(3).301

[14] N. George and B. Lethakumary, "A compact microstrip antenna for UWB applications," Microwave and Optical Technology Letters, vol. 57, no. 3, pp. 621-624, 2015, https://doi.org/10.1002/mop.28910.

[15] C.-Y. Sim, W.-T. Chung, and C.-H. Lee, "Novel band-notch UWB antenna design with slit ground plane," Microwave and Optical Technology Letters, vol. 50, no. 8, pp. 2229-2233, 2008, https://doi.org/ 10.1002/mop. 23621 .

[16] B. Saidaiah, A. Sudhakar, and K. P. Raju, "A New Olympic Ring Shaped Antenna for UWB Applications," Engineering, Technology \& Applied Science Research, vol. 6, no. 3, pp. 1010-1012, Jun. 2016, https://doi.org/10.48084/etasr.682.

\section{AUTHORS PROFILE}

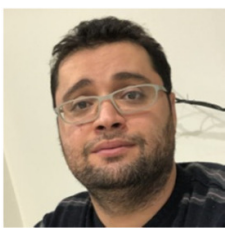

Mohamed Salah Karoui was born in Bizerte, Tunisia in 1979. He received the Electrical Engineering Degree from the National Engineering School of Sfax in 2003, the MSc degree on electronics in 2004, and the Doctorate on Electrical Engineering in 2010. He is currently working toward a HDR on Electrical Engineering. He joined the Higher Institute of Applied Sciences and Technology of Mateur in 2006. Currently, he is an Assistant Professor at the same institute. Also he is a member of the LETI Laboratory ENIS Sfax. His researches are focused on wideband antennas, bandwidth enhancement, RFID.

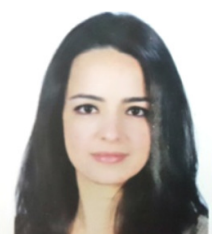

Nadia Ghariani was born in Sfax, Tunisia in 1984 She received the advanced technician diploma in Electronics and Communication from the Higher Institute of Electronics and Communication of Sfax Tunisia in 2006 and the Electrical Engineering Degree from the National Engineering School of Sfax -Tunisia in 2009, the research MSc degree in Electronics in 2010 and the Doctorate on Electrical Engineering at the same EEngineering School in 2016. She is a member of the LETI Laboratory ENIS Sfax - Tunisia. Her current research interests are UWB localization systems in indoor environments and UWB antennas.

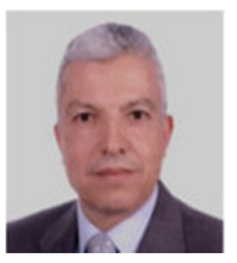

Mongi Lahiani was born in Sfax, Tunisia, in 1957. He received the Electrical Engineering Degree from the University of Sciences and Techniques of Sfax-Tunisia in 1984 and the Doctorate of Engineer in Measurement and Instrumentation from University of Bordeaux, France, in 1986. Since 1988, he is a Professor at Sfax University. He joined the National Engineering School of Sfax in 1990 and he is a Professor in the fields of analog electronics and microelectronics. His research interests are design of circuits in medical electronic and integration of microwave circuits of micro-strips with screen-printed thick films technology.

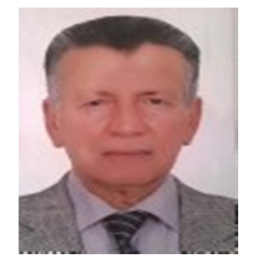

Hamadi Ghariani was born in Sfax, Tunisia, on July 1956. He received the Electrical Engineering Degree from the University of Sciences and Techniques of Sfax-Tunisia in1981, the DEA degree in 1981and his Doctorate of Engineer in 1983 in Measurement and Instrumentation from the University of Bordeaux France. He joined the National Engineering School of Sfax in 1984. Currently, he is a Professor in the same School. His research activities have been devoted to topics such as medical electronics, communication systems for medical telemetry, measure and instrumentation. 